\title{
INTENSIFICACIÓN Y DINÁMICA OCUPACIONAL EN EL PERÍODO PREHISPÁNICO TARDÍO DE LAS SIERRAS DE CÓRDOBA (ARGENTINA): UNA APROXIMACIÓN DESDE EL REGISTRO ARTEFACTUAL ÓSEO
}

\author{
INTENSIFICATION AND OCCUPATIONAL DYNAMIC DURING THE LATE \\ PREHISPANIC PERIOD IN THE SIERRAS OF CÓRDOBA (ARGENTINA): \\ A BONE TECHNOLOGY APPROACH
}

\author{
Matías Medina ${ }^{1}$ Natacha Buc ${ }^{2}$ y Sebastián Pastor ${ }^{1}$
}

\begin{abstract}
Se presenta el análisis del conjunto artefactual óseo de cuatro sitios arqueológicos correspondientes al período Prehispánico Tardío de las Sierras de Córdoba (ca. 1.100-360 años a.p., Argentina). El estudio tuvo como objetivo clasificar los artefactos en grupos morfológicos y determinar las actividades realizadas en los sitios. Los resultados indican la existencia de una tecnología ósea que utilizaba materiales disponibles localmente y se vinculaba con las necesidades de consumo de los grupos domésticos. También sugieren que la adopción de estrategias agrícolas, ca. 1.100 años a.p., fue acompañada por una intensificación de las prácticas de caza-recolección, con el desarrollo de nuevas tecnologías para la caza y el procesamiento de sus subproductos. Por último, se concluye que los asentamientos interpretados como bases residenciales exhibieron una mayor diversidad de artefactos óseos y evidencias concretas de su manufactura, lo cual refleja la realización de una amplia gama de actividades y tiempos de permanencia extendidos.

Palabras claves: Sierras de Córdoba, Holoceno Tardío Final, intensificación, movilidad residencial, tecnología ósea.
\end{abstract}

This paper presents the results of an analysis of the bone technology from four Sierras de Córdoba (Argentina) Late Prehispanic archaeological sites (ca. 1,100-360 BP). The aims of the study were to classify the bone tools into morphological groups and to determine the activities carried out at those sites. The results indicate bone technology was made with locally available materials and linked to the needs of small household groups. They also suggest that the adoption of small-scale agricultural strategies, ca. 1,100 BP, was accompanied by the intensification of hunting-gathering activities, which included the development of new technologies for hunting and processing their products. Finally, we conclude that the open-air residential sites exhibited a greater diversity of bone tools and concrete evidence of their manufacturing, which reflects a wider range of activities and a complex long-term occupational/abandonment history.

Key words: Sierras de Córdoba, Final Late Holocene, intensification, residential mobility, bone technology.

Los instrumentos elaborados sobre hueso y asta, a juzgar por su número y diversidad, ocuparon un lugar significativo dentro de las estrategias tecnológicas implementadas por los grupos humanos que habitaron las Sierras de Córdoba durante el período Prehispánico Tardío, ca. 1.100-360 años a.p. (Argüello de Dorsch 1983; Berberián 1984; González 1943, 1949; Marcellino et al. 1967; Menghin y González 1954; Serrano 1945). Sin embargo, su análisis tecnológico no ha recibido la misma atención que los conjuntos líticos o cerámicos, siendo excepcionales los casos en los que se derivaron hipótesis vinculadas con su funcionalidad o con las actividades realizadas dentro de los sitios (Rivero et al. 2008-09).
En este trabajo se presentan los resultados del análisis efectuado sobre el conjunto artefactual óseo obtenido en las excavaciones de cuatro sitios localizados en el sector central de las Sierras de Córdoba: C.Pun.39 y Las Chacras 2 (valle de Punilla), Arroyo Talainín 2 (valle de Salsacate) y Puesto La Esquina 1 (Pampa de Olaen). El estudio tuvo como objetivo clasificar los artefactos en grupos morfológicos de acuerdo con hipótesis funcionales y determinar las actividades realizadas en los sitios, estableciendo la relación de la tecnología ósea con la disponibilidad de otras materias primas, así como con las estrategias económicas y sociales implementadas por los grupos en estudio.

1 CONICET - Área de Arqueología y Etnohistoria del Centro de Estudios Históricos "Prof. Carlos S. A. Segreti”, M. C. del Corro 308, Córdoba (5.000), Argentina. paleomedina@yahoo.com.ar; pastorvcp@yahoo.com.ar

2 CONICET - Instituto Nacional de Antropología y Pensamiento Latinoamericano, 3 de Febrero 1378, Buenos Aires (1.426), Argentina.natachabuc@gmail.com 


\section{Características del Caso de Estudio}

Los sitios arqueológicos que forman parte de este estudio se localizan en el sector central de las Sierras de Córdoba, Argentina (Figura 1). Estas últimas constituyen un conjunto montañoso de baja altitud, con un amplio predominio de los entornos de Chaco Serrano que aportaron una variedad de recursos forestales (Prosopis spp., Geoffroea decorticans, Lithraea molleoides, etc.), suelos cultivables y fuentes hídricas permanentes. Los sectores más elevados de las sierras (1.500$3.000 \mathrm{msm}$ ), utilizados en forma complementaria por los grupos prehispánicos, contaron con valiosos recursos de caza, principalmente artiodáctilos de hábitos gregarios como guanacos (Lama guanicoe) y venados de las pampas (Ozotoceros bezoarticus).

El sitio C.Pun.39 se localiza en la cabecera norte del valle de Punilla, a $1.050 \mathrm{msm}$ (Figura 1). El entorno circundante es de Chaco Serrano, aunque empobrecido a causa de la altitud y el desarrollo de prácticas agropecuarias intensivas. Comprende un extenso terreno sedimentario en donde la actividad agrícola moderna puso al descubierto una alta diversidad de materiales arqueológicos (Argüello de Dorsch 1983; Medina 2009, 2010). Las excavaciones implicaron la intervención de $16 \mathrm{~m}^{2}$, alcanzándose profundidades máximas de $90 \mathrm{~cm}$. Los materiales indican la realización de actividades múltiples propias de los contextos domésticos, incluyendo la

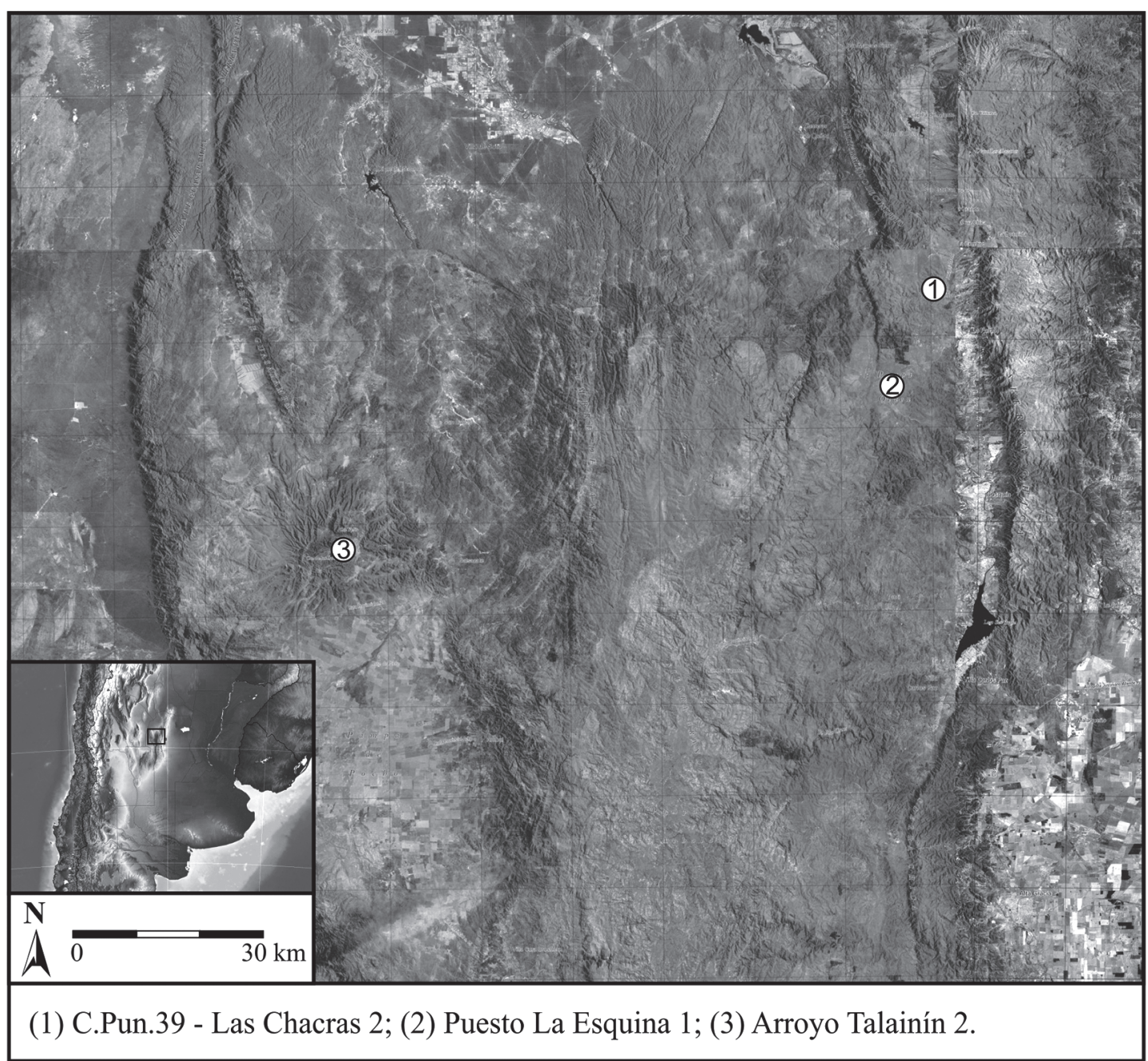

Figura 1. Ubicación geográfica de los sitios arqueológicos mencionados en el texto. Geographic location of the archaeological sites mentioned in the text. 
producción de alimentos (Medina 2010; Medina y Pastor 2012; Medina et al. 2009). Sobre muestras de carbón aproximadamente encolumnadas se obtuvieron tres dataciones radiocarbónicas cuyos resultados fueron $525 \pm 36$ a.p., $716 \pm 39$ a.p., y $854 \pm 39$ a.p. (Medina 2010). Estos fechados, sumados a valores excepcionales de tipos polínicos indicativos de disturbio antrópico, sugieren que el sitio pudo ser estacionalmente abandonado y reocupado a lo largo del tiempo (Medina et al. 2008).

Las Chacras 2 se localiza a $1.000 \mathrm{~m}$ al sur de C.Pun.39, sobre la cabecera de una pequeña quebrada lateral, a $1.060 \mathrm{msm}$ (Figura 1). Comprende un abrigo rocoso de $21 \mathrm{~m}^{2}$ cubiertos, en donde se excavaron $6 \mathrm{~m}^{2}$ y se alcanzaron profundidades máximas de $70 \mathrm{~cm}$. Toda la secuencia estratigráfica está dominada por materiales cerámicos y líticos cuyas características tecnológicas responden al período Prehispánico Tardío (ca. 1.100-300 años a.p.). Sin embargo, los resultados de las dataciones radiocarbónicas $-126 \pm 38$ a.p., $154 \pm 43$ a.p., $466 \pm 45$ a.p., $560 \pm 45$ a.p. y $3819 \pm 55$ a.p. - , la ausencia de una estratigrafía arqueológica claramente definida, la identificación de especímenes de fauna europea, cuevas y excrementos de vizcacha (Lagostomus maximus) indican que el sitio tiene una alta dinámica posdepositacional y una baja resolución cronológica (Medina et al. 2008).

Puesto La Esquina 1 es un sitio a cielo abierto localizado en una quebrada protegida de la Pampa de Olaen, a $1.160 \mathrm{msm}$, sobre terrenos con óptimas condiciones para el cultivo y la instalación de viviendas (Figura 1). Basándose en el registro arqueológico superficial se planteó que fue utilizado como un asentamiento residencial similar a C.Pun.39. Las excavaciones implicaron la apertura de $15 \mathrm{~m}^{2}$ y profundidades máximas de $60 \mathrm{~cm}$. La riqueza de los conjuntos artefactuales, que incluyen instrumentos vinculados al desmonte y roturado del terreno (azuelas líticas), así como la presencia de una posible estructura de vivienda, dan cuenta del uso agrícola-residencial del sitio (Medina 2009, 2010). Sobre muestras de carbón encolumnadas se obtuvieron dos dataciones radiocarbónicas cuyos resultados son $365 \pm 38$ a.p. y $362 \pm 43$ a.p. (Medina 2009). Tales resultados posicionan al asentamiento en momentos inmediatamente anteriores a la conquista española e indican la rápida formación del depósito (Medina 2009).

Arroyo Talainín 2 se localiza en el sector occidental del valle de Salsacate, en un entorno de Chaco
Serrano a $1.030 \mathrm{msm}$ (Figura 1). El sitio comprende un alero y un extenso talud con bloques graníticos donde se confeccionaron 81 útiles de molienda (morteros) (Medina et al. 2011; Pastor 2007). Las excavaciones implicaron la intervención de $8 \mathrm{~m}^{2}$ en la superficie cubierta del alero y en el talud, con profundidades máximas de $90 \mathrm{~cm}$. Entre los materiales mejor representados sobresalen los restos faunísticos (con más de 22.000 especímenes óseos), puntas de proyectil líticas y recipientes cerámicos cuyos tamaños son asociados a la preparación de volúmenes significativos de alimentos (Dantas y Figueroa 2008; Medina et al. 2011; Pastor 2007). Con carbón proveniente de una concentración ubicada en el interior del alero se obtuvo una datación de $740 \pm 60$ a.p. (Pastor 2007). En el caso del área exterior se fechó material proveniente de dos pisos superpuestos de sedimento consolidado, correspondientes a los momentos iniciales de la ocupación del lugar. Los resultados son $980 \pm 60$ a.p. y $900 \pm 50$ a.p. (Medina et al. 2011). El sitio fue utilizado recurrentemente a lo largo del período Prehispánico Tardío para procesar y consumir alimentos vegetales y animales, actividad que, a juzgar por la cantidad de morteros, el tamaño de los recipientes cerámicos y la densidad inusual de desechos faunísticos, implicó la participación simultánea de numerosos ocupantes.

\section{Metodología}

Se consideraron artefactos óseos a todas las piezas enteras o fragmentadas con algún tipo de modificación antrópica atribuida al uso o formatización, visibles a ojo desnudo y/o con lupa binocular a 25X (D'Errico et al. 2012).

Las piezas se clasificaron en grupos morfológicos siguiendo el protocolo de la Comisión de Nomenclatura Francesa (Camps-Fabrer 1966), con algunas modificaciones que atienden a las particularidades de los conjuntos (Buc 2010; Liesau von Letow-Vorbeck 1998; Scheinsohn 1997). En cada caso se definió la estructura física (identificación del hueso-soporte), métrica (largo, ancho y espesor) y morfológica. Finalmente, los grupos morfológicos fueron asociados a categorías funcionales definidas en la bibliografía internacional a partir de la ponderación de la morfología de las extremidades activas (forma, sección, contorno, etc.) y de las bases (presencia o ausencia de pedúnculo para insertar un mango, etc.), así como de los rastros macroscópicos de uso (estrías, redondeado, etc.). 
Los conjuntos y las actividades desarrolladas en los sitios fueron comparados estadísticamente en términos de riqueza a partir de la sumatoria del número de clases o categorías evitando su superposición (Grayson 1991). Se asumió que los conjuntos deberían exhibir diferencias relacionadas con su funcionalidad en los sistemas de asentamiento y subsistencia (Schlanger y Orcutt 1986). En este sentido, los sitios multipropósito, como Puesto La Esquina 1 y C.Pun.39, presentarían una mayor diversidad instrumental que aquellos vinculados a la realización de actividades específicas, como Las Chacras 2 o Arroyo Talainín 2.

\section{Resultados}

\section{C.Pun.39}

Se recuperó un total de 47 ítems, en su mayoría pequeños fragmentos de artefactos que no pudieron ser clasificados. Tres de ellos presentan decoración grabada y/o rastros de una pequeña perforación (Tabla 1, Figura 2). Como hueso-soporte se utilizaron en forma casi exclusiva astillas de huesos largos de macrovertebrados, con casos excepcionales en los que se identificaron elementos del esqueleto axial $\mathrm{o}$ astas de cérvidos.

Las puntas de proyectil pedunculadas son la categoría formal de mayor representación en el conjunto, con un total de siete fragmentos (Tabla 1). Con materiales provenientes de cuadrículas y niveles próximos se remontó una punta triangular de módulo alargado, contorno simétrico, sección biplana, aletas angulares y pedúnculo rectangular con aserrado marginal (Figura 3a). Este ejemplar muestra características estilísticas similares a las recuperadas en distintos sitios del área serrana (Berberián 1984; González 1943, 1949; Marcellino et al. 1967; Serrano 1945). Los restantes ejemplares corresponden en su mayoría a pedúnculos similares al de la pieza remontada, con un número mínimo de tres artefactos (Tabla 1). Uno de los fragmentos clasificado como indeterminado podría corresponderse con un pedúnculo. Si bien no presenta aserrado marginal, su clara forma cuadrangular, sección biplana, huellas de formatización diagonales y espesor de 2-3 mm, resultan similares a los registrados en el resto de las puntas. Dicha asignación incrementaría la frecuencia de cabezales óseos (Tabla 1).

El diseño simétrico y aerodinámico, así como otros atributos métricos (longitud de módulo, espesor, ancho del pedúnculo y masa), sugieren que estos cabezales formaron parte de un sistema de armas impulsado por arco, con empleo de astiles livianos (cf. Ratto 2003) e intercambiables (Keeley 1982; Loponte 2008; Pastor et al. 2005). La literatura etnográfica vincula el empleo de estas puntas con la captura de pequeños animales, fundamentalmente aves (Ellis 1997). Sin embargo, su poder de penetración asociado a su módulo alargado también las hizo aptas para la caza de mamíferos mediano-grandes (Loponte 2008; Pastor et al. 2005) o para la guerra (Pastor et al. 2012). Varios de los especímenes de C.Pun.39 muestran rastros macroscópicos de exposición al fuego (Tabla 1; sensu Shipman et al. 1984), por lo que no sólo informan acerca de eventos de caza y/o violencia interpersonal, sino también de la reparación de armas y descarte junto a fogones.

Además, se documentó un instrumento elaborado sobre asta de Cervidae cf. Ozotoceros bezoarticus con ápice romo, sección circular y huellas macroscópicas que permiten su adscripción a la categoría de retocador (Figura 3b; cf. Borella y Buc 2009). El extremo activo presenta un patrón de estrías largas y profundas ubicadas transversalmente al eje de la pieza sobre una de sus caras (Figura 3c), que es similar al presentado por otros autores en piezas experimentales utilizadas en el retoque de artefactos líticos (Castel et al. 2003; D'Errico et al. 2012; Mozota Holgueras 2008; Nami y Scheinsohn 1997; Santander y López 2012, entre otros). Esto complementa lo observado en los conjuntos líticos de C.Pun.39, señalando la formatización final de instrumentos mediante el lascado por presión.

Entre los instrumentos formales también se identificó un punzón de sección circular, cuerpo cóncavo-convexo y base fracturada (Figura 3d). $\mathrm{El}$ instrumento se corresponde con el "tipo 1" o "perforadores" en la clasificación de Camps-Fabrer (1966:126), y fue formatizado sobre una forma base obtenida mediante el marcado longitudinal y posterior seccionamiento de un hueso largo de macrovertebrado indeterminado (cf.Yesner y Bonnischen 1979). El punzón, junto a cuatro fragmentos de ápices con sección cóncavo-convexa y plano convexa, apropiados para hendir y perforar, sugieren que en C.Pun.39 se realizaron actividades vinculadas con el tratamiento secundario de cueros y pieles. Estudios experimentales y etnográficos advierten sobre la posibilidad de que los punzones también hayan sido empleados en la manufactura de cestas y/o redes de fibras vegetales (Buc 2005; 


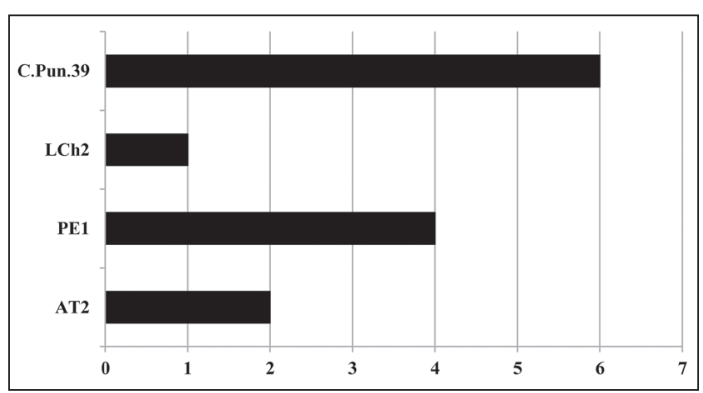

Figura 2. Riqueza de los artefactos óseos recuperados en C.Pun.39, Las Chacras 2, Puesto La Esquina 1 y Arroyo Talainín 2. Abundance of bone tools from C.Pun.39, Las Chacras 2, Puesto La Esquina 1 and Arroyo Talainín 2.
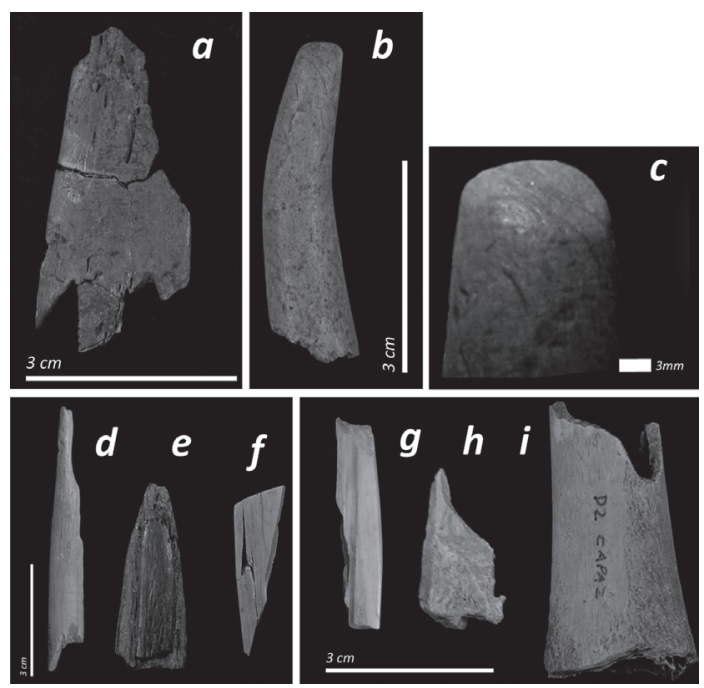

Figura 3. Artefactos elaborados en hueso del sitio C.Pun.39: (a) punta de proyectil pedunculada; (b) retocador de asta; (c) Ápice de retocador (C.Pun.39-7); (d) punzón; (e) alisador; (f) espátula; (g-i) elementos descartados en el proceso de manufactura. Bone tools from C.Pun.39: (a) triangular-stemmed projectile point; (b) flaker made of antler; (c) flaker end (C.Pun.39-7); (d) awl; (e) smoother; $(f)$ spatula; ( $g$-i) elements discarded during the manufacturing process.

Stone 2011) similares a las observadas en las improntas de tiestos cerámicos (Argüello de Dorsch 1983:53; Medina 2010). La tecnología ósea, de esta manera, puede reflejar el uso de objetos elaborados con fibras vegetales o tejidos blandos de animales, con una baja visibilidad en el registro arqueológico, pero gran importancia entre sociedades que cambian estacionalmente de residencia y requieren artefactos transportables (Stone 2011).

Un instrumento de sección biplana, extremo apical redondeado y superficie alisada fue clasificado como alisador (Figura 3e). Observado en lupa binocular presenta un patrón bien desarrollado de estrías transversales agrupadas, similares al de piezas del Holoceno Tardío del humedal del Paraná inferior (ca. 1.100-600 a.p.) a los que se atribuyó como funcionalidad primaria el alisado/pulido de cerámica junto con el procesado de pieles y vegetales (Buc 2010). Las semejanzas con los alisadores no se reducen a su estructura morfológica y posibles rastros de uso, sino también al estar elaborado sobre una costilla, uno de los elementos comúnmente seleccionados para manufacturar estos artefactos (Liesau von Lettow-Vorbeck 1998; Mujika Alustiza 2008; Vitezovic 2011). La hipótesis funcional que asocia el instrumento con el pulido final de vasijas cerámicas para mejorar su impermeabilidad se refuerza con el registro en C.Pun.39 de masas de arcilla cocida, vinculadas a la manufactura local de alfarería, así como abundantes tiestos con estrías de pulimento (Medina 2010). Instrumentos similares fueron observados en otros sitios de actividades múltiples de la región, como La Mandinga y Potrero Garay (Berberián 1969, 1984).

Un pequeño fragmento de instrumento biplano, con superficies brillosas, contorno redondeado y extremo pulido fue clasificado como espátula (Figura 3f; cf. Camps-Fabrer 1966:98). Se ha propuesto que este tipo de artefactos fueron utilizados para tareas similares a los alisadores, aunque su modo de acción sería también longitudinal, incluyendo el trabajo de diversos materiales como pieles, vegetales (p.ej., Cristiani 2008; Vitezovic 2011) y cerámica (Camps-Fabrer 1966).

Por último, se recuperó una astilla que conserva huellas de lo que habría sido el marcado para seccionar el hueso longitudinalmente (Figura 3g; cf. Yesner y Bonnischen 1979), otra astilla con huellas de desbastado para su seccionamiento transversal (Figura 3h; cf. David 2004) y un tubo de diáfisis con aserrado perimetral (Figura 3i; cf. Acosta 2000), en todos los casos sobre huesos largos de macrovertebrados indeterminados. Las tres técnicas están vinculadas con la cadena operativa de elaboración de instrumentos óseos, principalmente con la segmentación del hueso en unidades menores para su formatización, sugiriendo la realización de estas actividades en el sitio. Es de particular interés el espécimen con marcas de aserrado perimetral, ya que su diseño permite obtener dos caras planas de ca. $3 \mathrm{~mm}$ de espesor que se ajustan a las preformas o módulos necesarios para la elaboración de puntas de proyectil. 


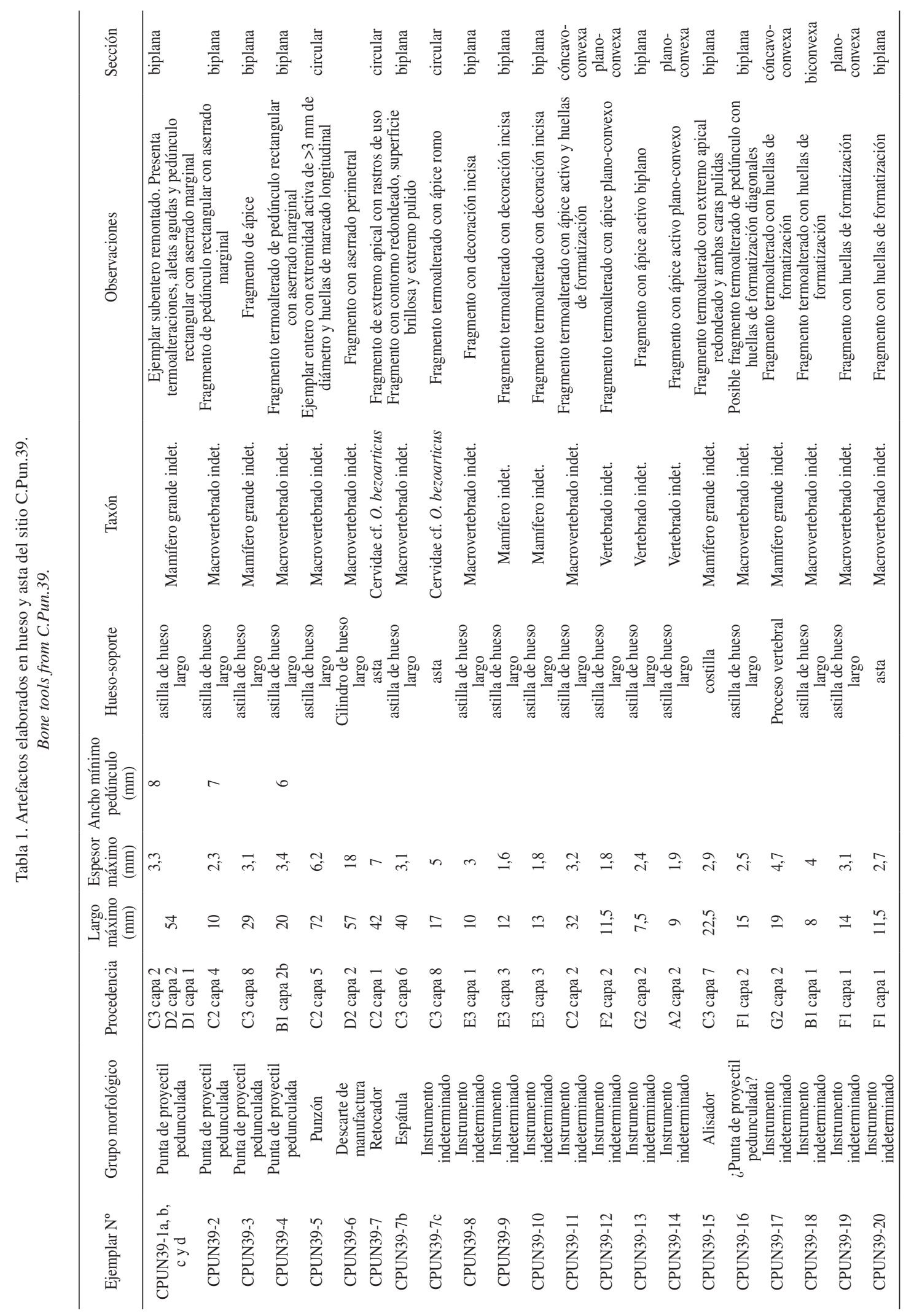




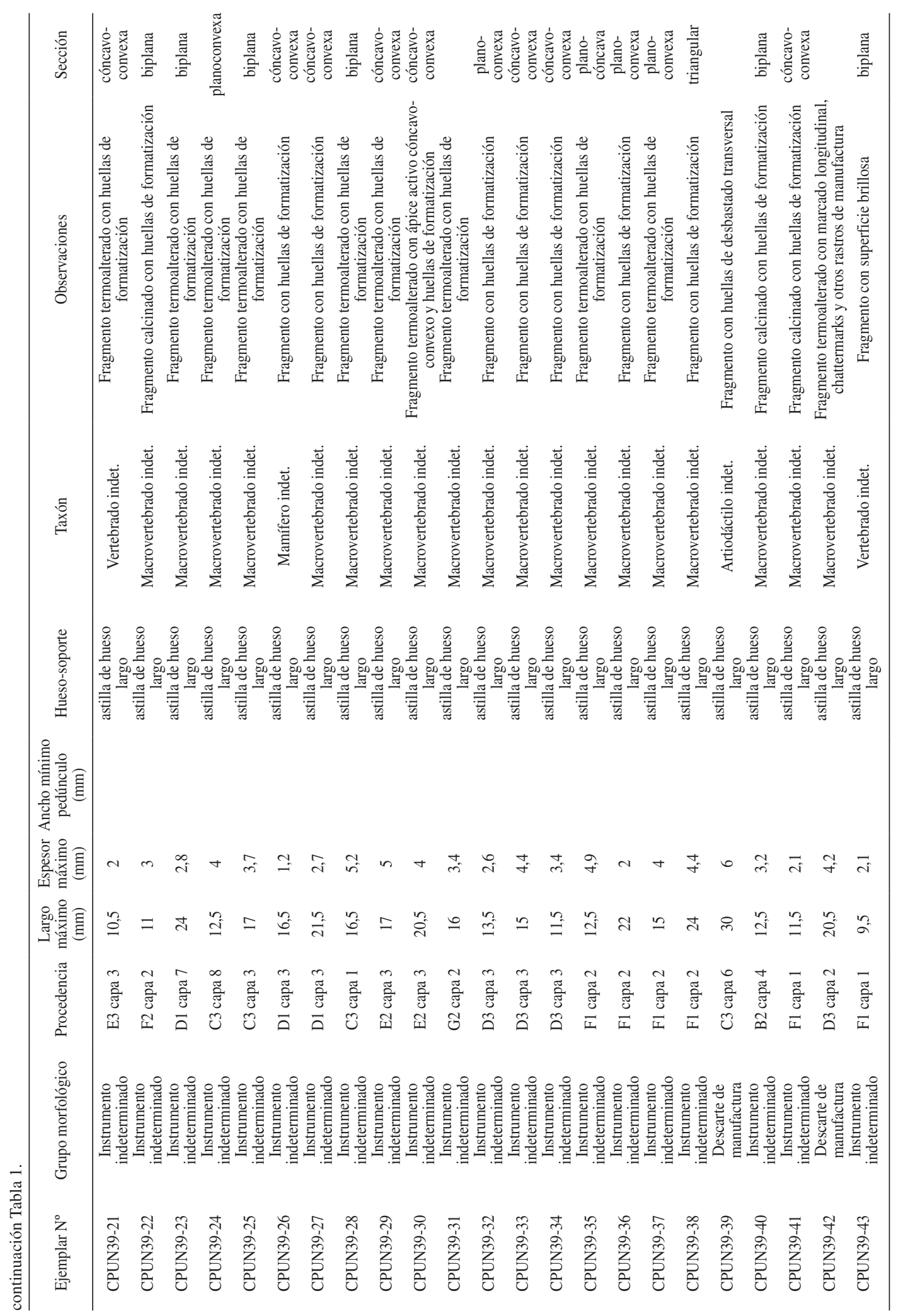




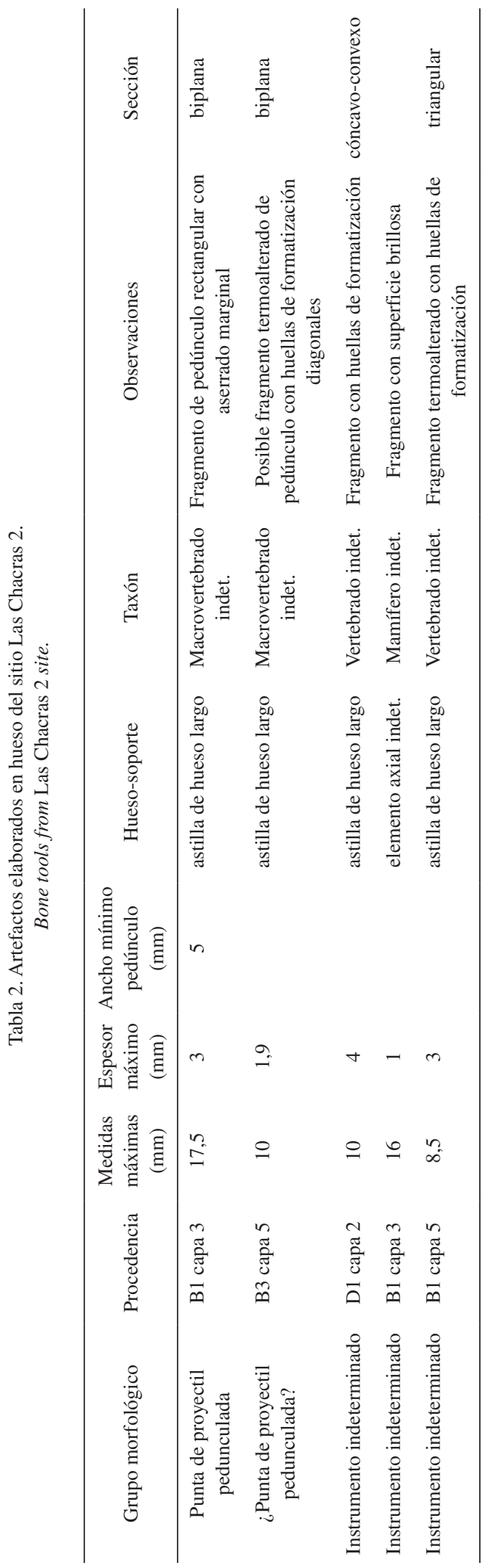

\section{Las Chacras 2}

A pesar del tamaño de la superficie intervenida, en Las Chacras 2 sólo se recuperó un fragmento de pedúnculo rectangular con aserrado marginal correspondiente a una punta de proyectil. El mismo indica actividades de reparación de armas llevadas a cabo en el sitio (Tabla 2; Figura 2). Otro fragmento indeterminado también podría ser atribuido a un pedúnculo de acuerdo con su espesor y a las huellas de formatización (Tabla 2). Las piezas restantes resultaron indeterminadas a nivel morfológico.

\section{Puesto La Esquina 1}

En la excavación de Puesto La Esquina 1 se recuperaron 32 fragmentos de instrumentos óseos, en su mayor parte inclasificables (Tabla 3 y Figura 2). Los huesos-soporte estuvieron exclusivamente representados por elementos apendiculares de macrovertebrados, con casos excepcionales en los que fue posible su adscripción a taxones específicos. La utilización de un metatarso de $O$. bezoarticus y de una falange primera de Lama sp., especies que dominan los conjuntos arqueofaunísticos, llevó a sostener que el descarte posterior a su consumo proveyó los elementos necesarios para implementar esta estrategia tecnológica.

Las puntas pedunculadas están representadas por un ejemplar subentero, así como por fragmentos de limbos y pedúnculos con aserrado marginal (Tabla 3; Figura 4a-b). A partir de la frecuencia de estos últimos se estimó un número mínimo de tres ejemplares, aunque dos fragmentos indeterminados podrían incrementar el número de pedúnculos y de cabezales. Se trata de morfologías triangulares, de contorno simétrico, sección biplana, módulo alargado, aletas agudas y pedúnculo con aserrado marginal, estilísticamente similares a las recuperadas en C.Pun.39. El patrón de fractura del ejemplar PE1-1 (Figura 4a), posiblemente vinculado con su utilización (Cristiani 2008; Knecht 1997, Petillon 2006), junto a varios ejemplares quemados, indica que en el sitio se repararon armas con empleo del fuego para eliminar el mastic, recuperar los astiles y enmangar nuevos cabezales.

También se registró un elemento sobre una falange primera de Lama sp. que a partir de la morfología de su extremo activo y rastros observados con lupa binocular, similares a los discutidos en el caso de C.Pun.39, puede clasificarse como retocador 
(Figura 4c-d). El artefacto sugiere la formatización final de útiles líticos mediante la remoción de pequeñas lascas por presión, en forma consistente con lo observado a partir del análisis del conjunto lítico. La presencia de dos leznas y un punzón formatizado sobre un metapodio de Ozotoceros bezoarticus (Figura 4e-g) indicarían el tratamiento secundario de pieles y/o vegetales. A diferencia del ejemplar recuperado en C.Pun.39, el punzón se ajusta al "tipo 2" de Camps-Fabrer (1966:107), conservando parte de la epífisis proximal (Figura 4g).

\section{Arroyo Talainín 2}

En Arroyo Talainín 2 se recuperaron 36 fragmentos de instrumentos óseos (Tabla 4 y Figura 2). La evidencia apunta a la presencia mayoritaria de huesos largos de macrovertebrados como soportes, aunque también se documentó un artefacto elaborado sobre un osteodermo de Euphractinae.

La categoría formal de mayor representación comprende a las puntas de proyectil, con un total de 12 fragmentos y un número mínimo de 11 ejemplares (Tabla 4). Cuatro de ellos se encuentran subenteros y/o con fracturas que pueden ser atribuidas al uso, observándose los caracteres comunes para la región, con un importante módulo de alargamiento, aletas agudas y pedúnculos rectangulares con aserrado marginal (Figura 5a). El resto de los especímenes corresponde a fragmentos de pedúnculos con aserrado marginal, en su mayoría termoalterados. La alta frecuencia de pequeños fragmentos de instrumentos indeterminados de sección biplana, espesores ca. 2-3 $\mathrm{mm}$ y huellas de formatización diagonales podría incrementar en forma significativa el número de cabezales óseos.

El conjunto sugiere que la realización de eventos de caza y de reparación de armas junto a fogones fueron actividades recurrentes en Arroyo Talainín 2. Sin embargo, la presencia de dos especímenes de metapodios proximales de Lama sp. con fractura longitudinal por percusión bipolar, aserrado perimetral y marcas de formatización, permiten sostener que en el sitio se prepararon módulos alargados con los que luego se pudo manufacturar diversos instrumentos, principalmente puntas de proyectil (Figura $5 b$ ).

Cuatro fragmentos de instrumentos indeterminados con ápices biplanos y biconvexos indican la realización de actividades que implicaron hendir, perforar y/o trabajar sobre materiales blandos, como
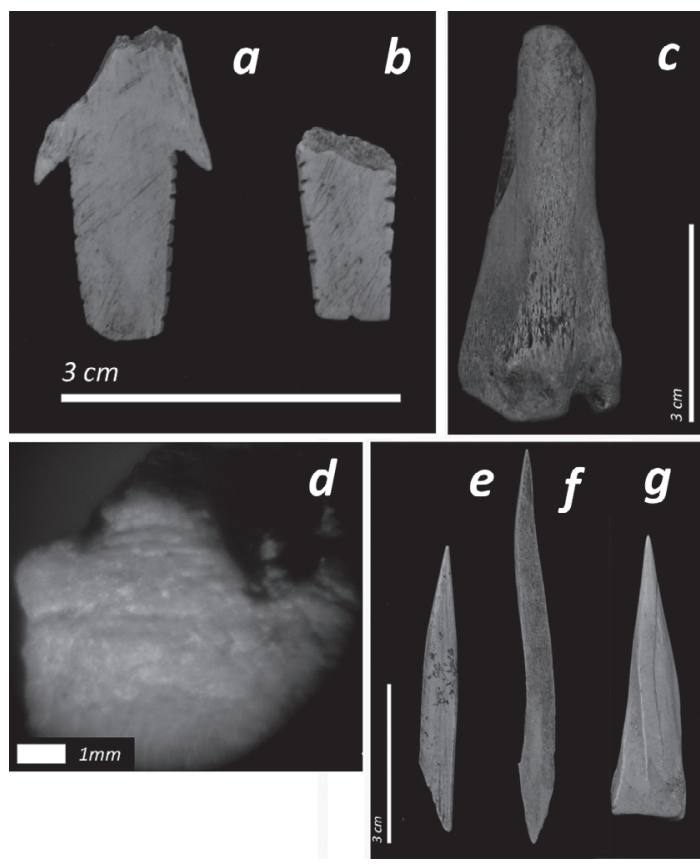

Figura 4. Artefactos elaborados en hueso del sitio Puesto La Esquina 1: (a) punta de proyectil pedunculada con posible fractura por uso; (b) pedúnculo de punta de proyectil; (c) retocador; (d) ápice de retocador, lupa binocular 15X (PE1-9); (e-f) leznas; (g) punzón.

Bone tools from Puesto La Esquina 1 site: (a) triangularstemmed projectile point probably fractured due to use; (b) stem of triangular-shaped projectile point; (c) flaker; (d) flaker end, light microscope 15X (PE1-9); (e-f) pin-like tools; ( $g$ ) awl.

pieles o fibras vegetales (Figura 5c). El registro de una placa dérmica de armadillo con rastros de formatización en su cara ventral, así como de un fragmento de instrumento indeterminado con decoración grabada en una de sus caras, indica un posible uso como adornos personales asociados a armas u otros objetos de uso cotidiano.

\section{Discusión}

El estudio morfológico y de las actividades realizadas en los sitios determinó que los instrumentos elaborados en hueso y asta contribuyeron a solucionar problemas de diferentes órdenes. Punzones, leznas, alisadores, retocadores y espátulas vincularon la tecnología ósea con la confección de otros artefactos necesarios para la vida cotidiana, ya sean textiles, instrumentos líticos, cerámicos y posiblemente cestos. Los instrumentos decorados con motivos grabados, aun cuando su fragmentación 


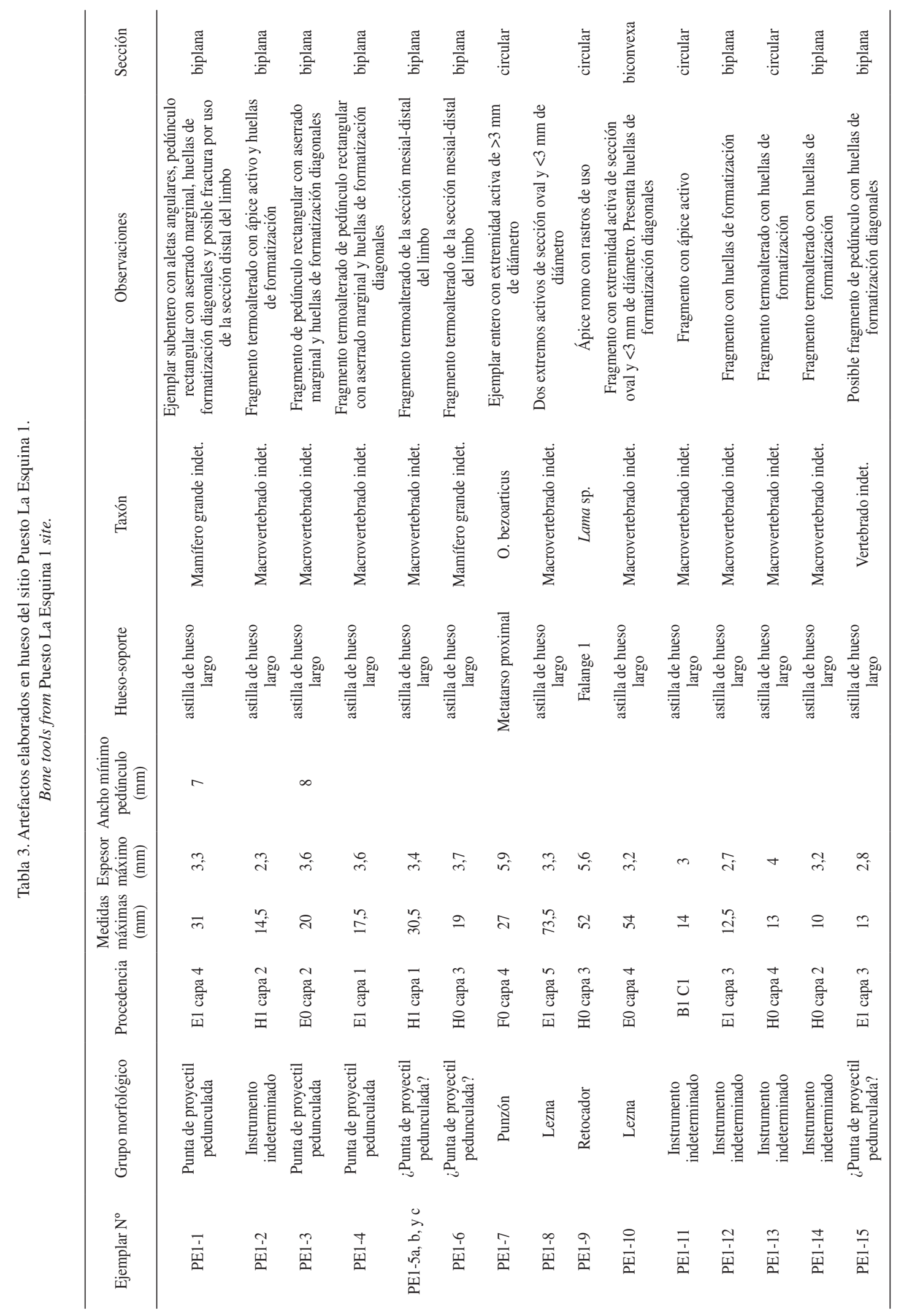




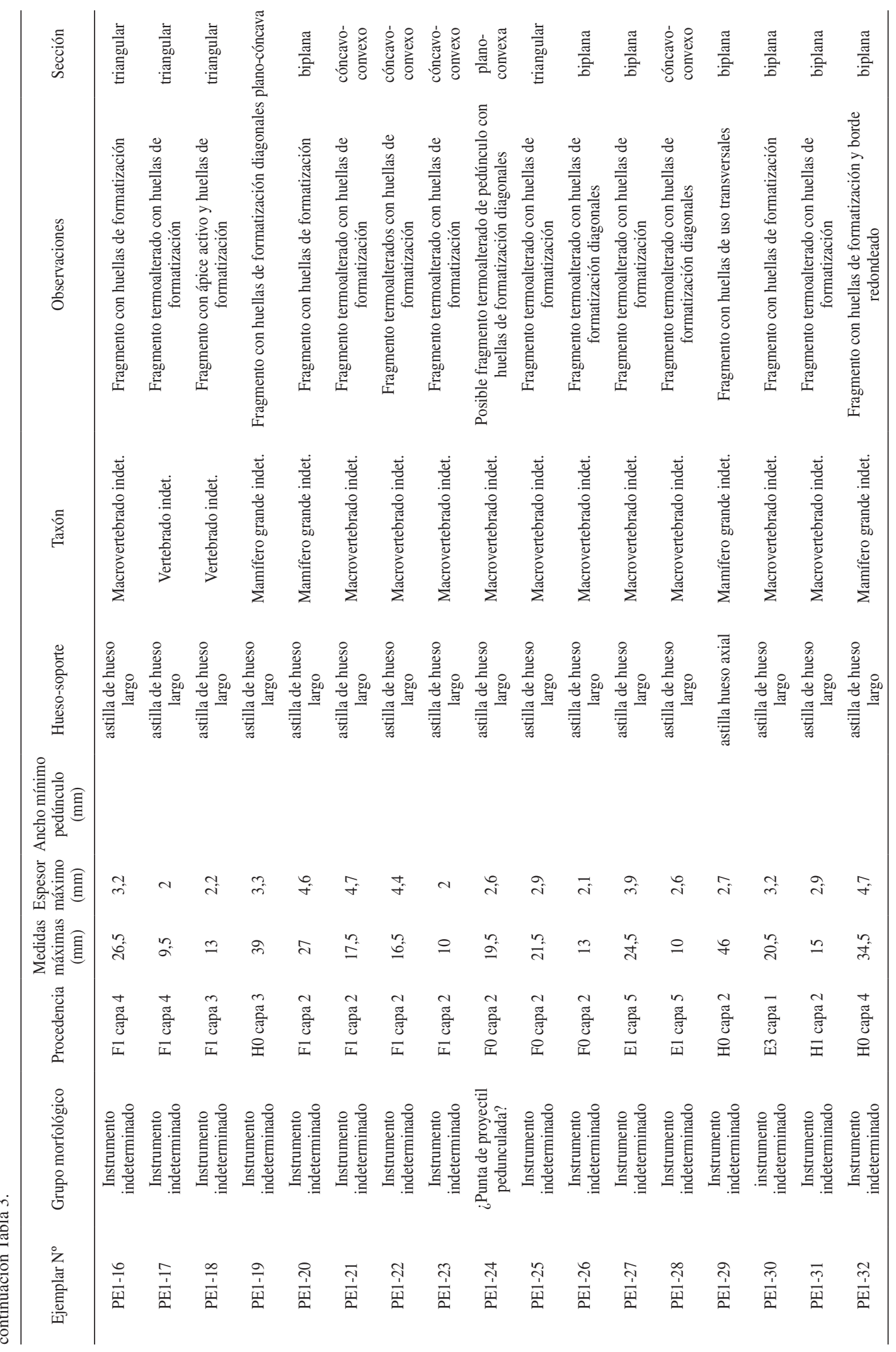



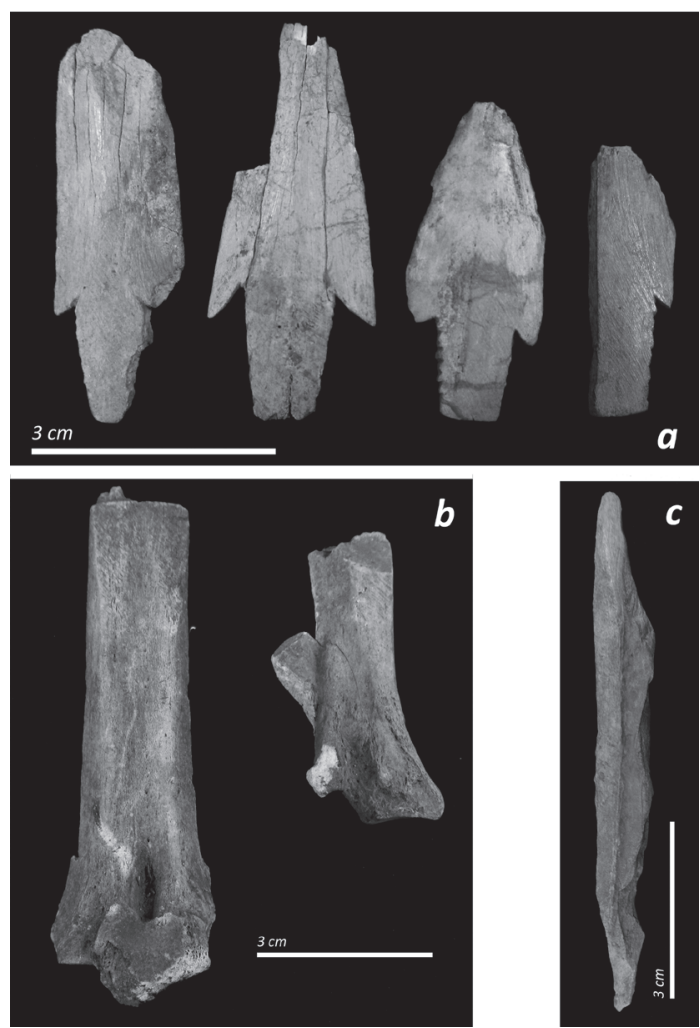

Figura 5. Artefactos elaborados en hueso del sitio Arroyo Talainín 2: (a) puntas de proyectil pedunculadas; (b) descarte de manufactura; (c) instrumento indeterminado con ápice activo de sección biplana.

Bone tools from Arroyo Talainín 2: (a) triangular-stemmed projectile points; (b) elements discarded during the manufacturing process; (c) indeterminate pointed tool with biplane section.

impide su clasificación, indican que la tecnología ósea también se vinculaba a aspectos simbólicos no directamente vinculados con la subsistencia. $\mathrm{La}$ producción de la mayoría de estos útiles podría ser definida como expeditiva (Nelson 1991), ya que se manufacturaron informalmente con subproductos del descarte de las actividades de subsistencia.

Las puntas de proyectil, uno de los artefactos óseos de mayor representación en los sitios, conforman una excepción. La preparación de módulos adecuados para su manufactura, su grado de formatización y diseño estandarizado se compensaron con un óptimo enmangue y larga vida funcional, sobre todo por su menor susceptibilidad a la fractura que las de material lítico (Knecht 1997), indicando comportamientos conservativos y confiables (Nelson 1991; ver también Bleed 1986). Estas características de diseño, en parte compartidas con los cabezales líticos y en un contexto donde priman las estrategias tecnológicas expeditivas, sugieren que la captura de presas silvestres no era una actividad complementaria. Por el contrario, integraría junto a la agricultura y la recolección un sistema económico de tipo mixto. En este contexto, las puntas de proyectil integradas a un sistema de armas impulsado por arcos habrían jugado un rol crucial para abatir presas pequeñas y medianograndes con radios de captura distintos, incluso en ambientes de vegetación cerrada. La importancia de las actividades cinegéticas también está señalada por la abundancia de restos óseos de guanacos, venados de las pampas, así como una amplia gama de aves, reptiles y pequeños mamíferos con claras evidencias de procesamiento antrópico o de haber sido potencialmente consumidos (Medina 2009; Medina y Pastor 2012; Medina et al. 2011; Rivero et al. 2010 $)^{1}$. La ocupación intensiva de ambientes poco favorables para la agricultura pero ricos en recursos de caza, como las pampas de altura o los bordes de la llanura occidental, también argumentan a favor de esta propuesta (Pastor 2010; Pastor y Medina 2005; Recalde 2008-2009).

La diversidad del instrumental óseo no puede ser explicada por la falta de materias primas líticas. La disponibilidad y distribución de rocas de regular calidad para la talla es prácticamente continua en el paisaje serrano, sobre todo en lo que hace a las variedades de cuarzo (Pastor y Rivero 2009; Rivero 2009). Aun cuando la disponibilidad de rocas es un factor importante para el desarrollo de artefactos en hueso y asta, el caso arqueológico de Córdoba demuestra que no se trata de un simple reemplazo del material lítico, sino que es necesario considerar otras variables no menos importantes, como las propiedades particulares de la materia prima ósea y la base de recursos explotados (Bamforth y Bleed 1997; Buc y Silvestre 2006; Luik et al. 2011). En este contexto, ambas tecnologías fueron utilizadas en forma complementaria: mientras que en el conjunto óseo predominan los instrumentos con "puntas", de ápice agudo o romo, para perforar materiales blandos y/o elaborar otros artefactos (incluso en rocas silíceas), en el lítico dominan los "filos", comúnmente utilizados para trozar presas y/o trabajar materiales duros como madera, hueso o raspar cueros (Buc y Silvestre 2006). La presencia de elementos con marcas de aserrado perimetral o longitudinal, así como de desbastado transversal (que requieren de filos) señala cómo las tecnologías líticas y óseas funcionaron de 
manera integrada. Aun cuando las puntas de proyectil e instrumentos perforantes también fueron elaborados en roca, su utilización combinada resultó coherente en un período donde se diversificaron las actividades de subsistencia, el procesamiento de sus productos y se incrementaron las tensiones sociales, con pruebas concretas de violencia interpersonal (Medina 2009, 2010; Medina et al. 2011; Pastor 2010; Pastor et al. 2012).

Las puntas de proyectil y el posible alisador estuvieron íntimamente relacionados con las nuevas necesidades de una economía de amplio espectro, ya sea para cazar animales o elaborar artefactos involucrados en el procesamiento y almacenamiento de los productos agrícolas y de recolección. Los restantes instrumentos, como retocadores, espátulas, punzones, leznas y fragmentos con motivos grabados, no resultan ajenos a las restantes líneas de evidencia y pueden ser vinculados con el incremento en el procesamiento de los subproductos de caza, como cueros y pieles, así como con la redefinición de los roles sociales de los individuos.

En lo que toca específicamente a la funcionalidad de los sitios, los instrumentos óseos acompañaron las expectativas sostenidas inicialmente. Los asentamientos interpretados como bases residenciales (C.Pun.39 y Puesto La Esquina 1) exhibieron una mayor riqueza artefactual que aquellos interpretados como de propósitos especiales (Las Chacras 2 y Arroyo Talainín 2). Aun cuando el volumen de las intervenciones estratigráficas difirió en forma sustancial, es difícil atribuir estos valores a una simple relación estadística con el tamaño de la muestra (Grayson y Cole 1998). En cambio, las diferencias de riqueza parecen estar asociadas con el lugar que ocuparon los sitios dentro de los sistemas de movilidad y subsistencia tardíos (Schlanger y Orcutt 1986).

Puesto La Esquina 1 y C.Pun.39 fueron campamentos base que reflejan la concentración estival de un grupo de unidades domésticas para realizar actividades agrícolas, recolectar y capturar pequeños animales, así como procesar, almacenar y consumir sus productos ${ }^{2}$. También fueron locus donde se manufacturaban diversos artefactos que luego serían utilizados a lo largo del año, sobre todo aquellos que demandan cierta estabilidad residencial y/o combustible adecuado para su elaboración, como los recipientes cerámicos (Medina 2010). Los datos de Puesto La Esquina 1 sugieren que los materiales se depositaron en una serie de eventos próximos en el tiempo, mientras que C.Pun.39 presenta evidencias de múltiples ocupaciones e hiatos entre las mismas (Medina y Pastor 2012; Medina et al. 2008). De esta manera, no es sorprendente que C.Pun.39 y Puesto La Esquina 1 exhiban una mayor diversidad de instrumentos óseos y/o evidencias concretas de su manufactura, reflejando la realización de una amplia gama de actividades y tiempos de permanencia extendidos.

La baja riqueza artefactual del alero Las Chacras 2 y Arroyo Talainín 2, con el dominio absoluto de puntas de proyectil, señala el desarrollo de un menor rango de tareas (Schlanger y Orcutt 1986). Las Chacras 2 probablemente fue ocupado mediante estadías episódicas dirigidas a captar y procesar recursos que no requirieron la demanda de instrumentos óseos, mientras que Arroyo Talainín 2 se ocupó recurrentemente en ciertas épocas del año para obtener, procesar y consumir alimentos a escalas extradoméstica o comunitaria. Los conjuntos cerámicos, líticos, faunísticos y arqueobotánicos recuperados en C.Pun.39, Las Chacras 2, Puesto La Esquina 1 y Arroyo Talainín 2, así como las condiciones topográficas y de emplazamiento, acompañan a estos planteos (Medina 2010; Medina y Pastor 2012; Medina et al. 2009; Medina et al. 2011; Pastor 2007).

\section{Conclusiones}

El estudio de los artefactos elaborados en hueso y asta permitió una aproximación a las prácticas económicas y de uso del espacio, así como a aspectos de la organización social durante el período Prehispánico Tardío. La información aquí presentada expresa la existencia de una tecnología ósea que utilizaba materiales disponibles localmente y se vinculaba a las necesidades de consumo de las unidades domésticas. Por otro lado, también indica que la adopción de estrategias agrícolas, ca. 1.100 años a.p., fue acompañada por la intensificación de las prácticas extractivas, con el desarrollo de nuevas tecnologías para la caza y el procesamiento de sus subproductos. Otras evidencias no tratadas en profundidad, como la composición taxonómica de los conjuntos faunísticos y arqueobotánicos, el uso de los distintos microambientes serranos y el sostenimiento de elevados niveles de movilidad (con fases de dispersión estacional), refuerzan las ideas aquí planteadas (Medina y Pastor 2012; Medina et al. 2008; Medina et al. 2009; Pastor y Medina 2005; Recalde 2008-2009). 


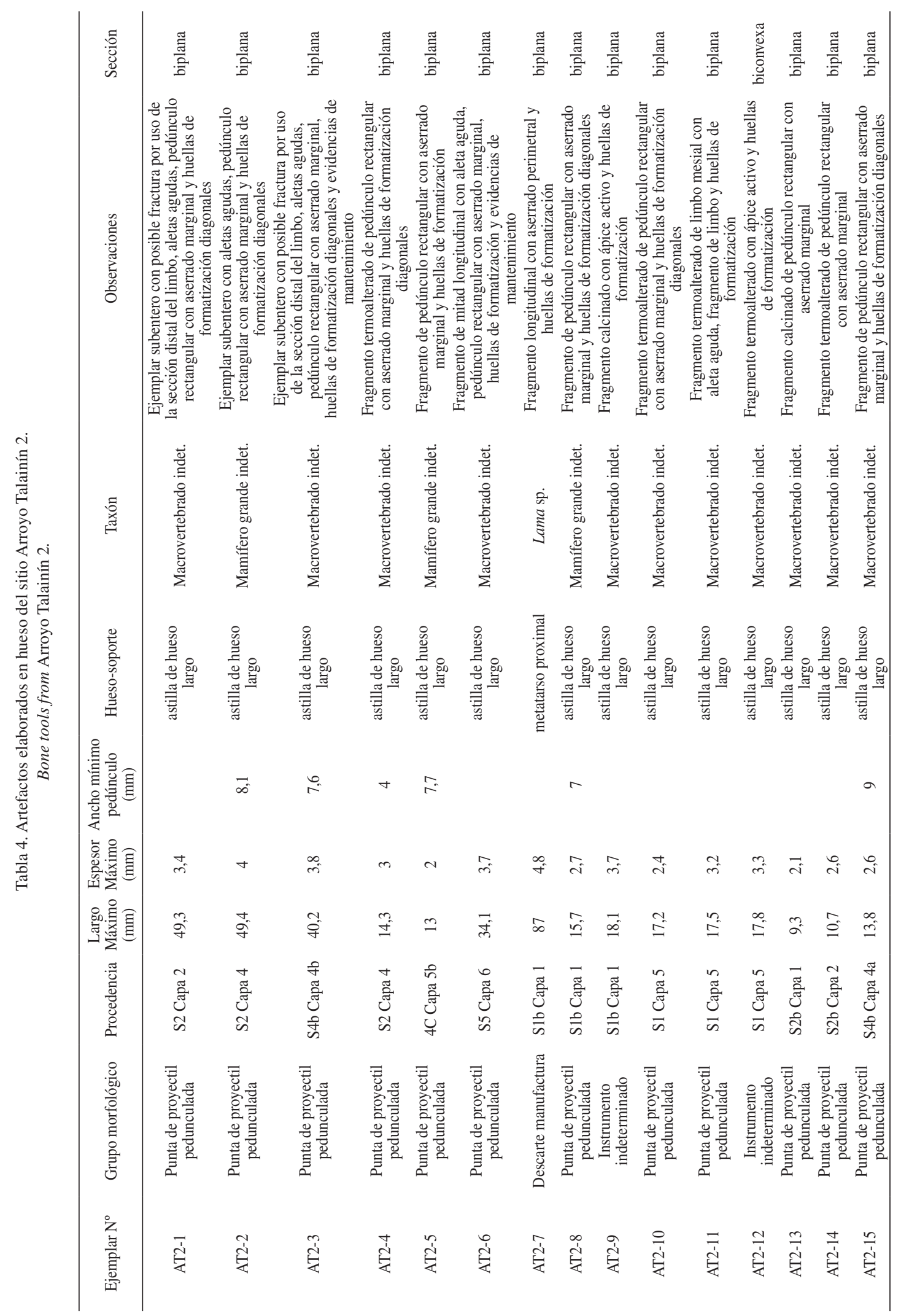




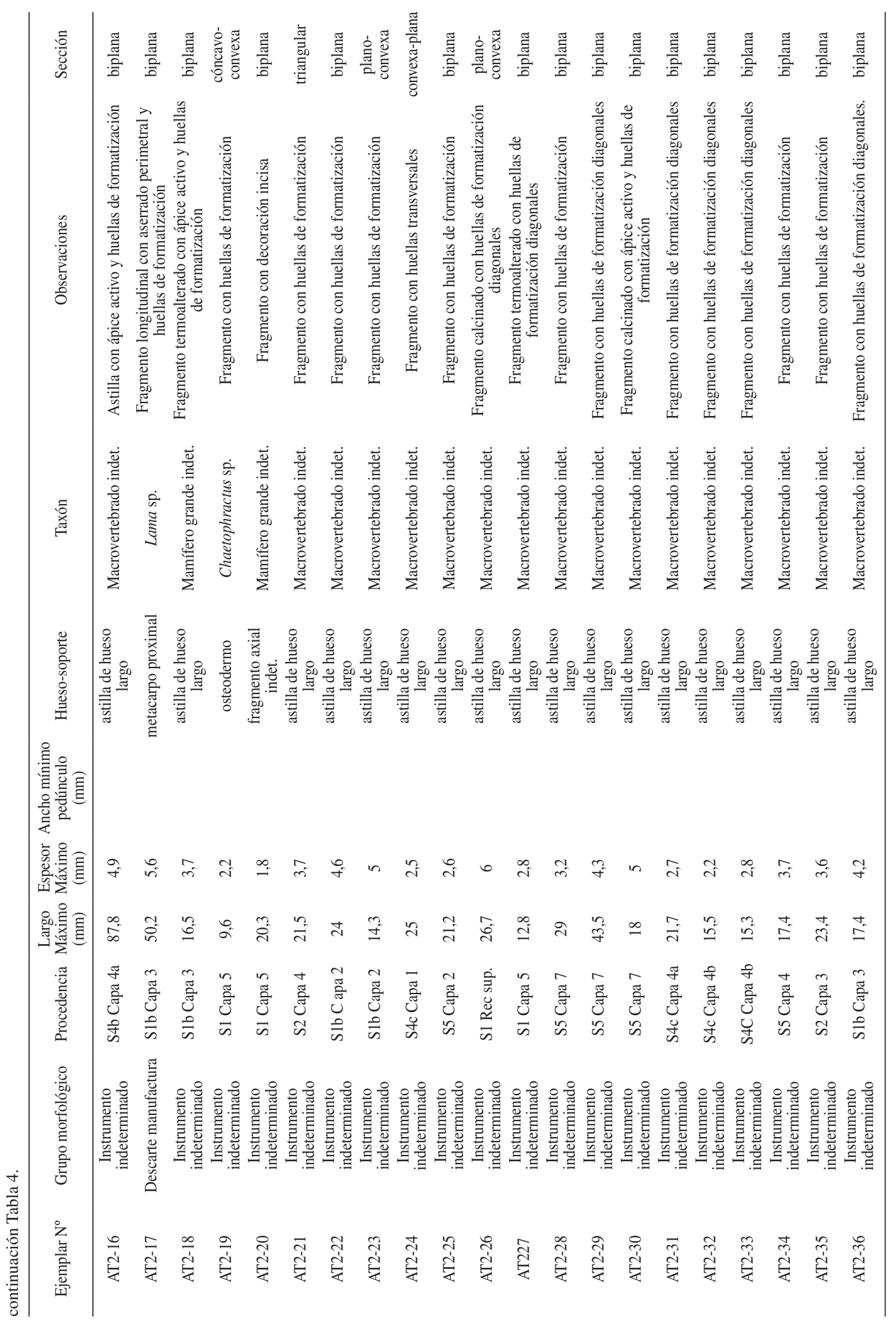


En este trabajo se realiza una exploración preliminar de esta problemática, en gran parte debido a que los análisis sobre conjuntos artefactuales óseos aún son fragmentarios y no se integran con estudios de microdesgaste. Esto obliga a incrementar la base de datos mediante nuevas excavaciones, la incorporación de sitios aún no analizados desde esta perspectiva y la comparación de rastros microscópicos de uso en piezas arqueológicas con bases actualísticas de referencia (Buc 2011; Cristiani 2008; D'Errico et al. 2012; Stone 2011 entre otros). La información derivada reforzará o modificará las implicancias aquí expuestas.
Agradecimientos: Este trabajo forma parte del proyecto "Condiciones de posibilidad de la reproducción social en sociedades prehispánicas y coloniales tempranas en las Sierras Pampeanas (República Argentina)", que cuenta con un subsidio otorgado por el CONICET (PIP 112-200801-02678). Deseamos expresar nuestro reconocimiento al Dr. Eduardo Berberián, director del proyecto, así como a Timothy Jull, del NSF Arizona Facility (grant EAR01-15488), por su colaboración con las dataciones radiocarbónicas. Pablo Giorno participó en las etapas iniciales del análisis de los materiales. Por último, a los evaluadores anónimos, cuyas sugerencias contribuyeron a mejorar la calidad del manuscrito.

\section{Referencias Citadas}

Acosta, A. 2000. Huellas de corte relacionadas con la manufactura de artefactos óseos en el nordeste de la provincia de Buenos Aires. Relaciones de la Sociedad Argentina de Antropología XXV:159-178

Argüello de Dorsch, E. 1983. Investigaciones arqueológicas en el departamento Punilla (Provincia de Córdoba-Rep. Argentina). Sitio C.Pun.39. Comechingonia 1:41-60.

Bamforth, D. y P. Bleed 1997. Technology, flaked stone technology and risk. En Rediscovering Darwin: Evolutionary Theory and Archaeological Explanation, editado por M. Barton y A. Clark, pp. 109-139. Archaeological Papers of the American Anthropological Association $N^{\circ}$ 7. American Anthropological Association, Arlington.

Berberián, E.1969. Investigaciones arqueológicas en Cosquín. Revista Ilustrada Cosquín 8.

- - - 1984. Potrero de Garay: una entidad sociocultural tardía de la región serrana de la Provincia de Córdoba (Rep. Argentina). Comechingonia 4:71-138.

Bleed, P.1986. The optimal design of hunting weapons: maintainability or reliability. American Antiquity 51:737-747.

Borella, F. y N. Buc 2009. Ópticas y ópticos. Una aproximación a la tecnología ósea en la Bahía de San Antonio (Río Negro), Argentina. En Arqueología de Patagonia: Una Mirada desde el Último Confín, editado por M. Salemme, F. Santiago, M. Álvarez, E. Piana, M. Vázquez y M. Mansur, pp. 421-433. Editorial Utopías, Ushuaia.

Buc, N.2005. Análisis microscópico de instrumentos óseos del humedal del Paraná Inferior. Una primera aproximación experimental. En Entre Pasados y Presentes. Trabajos de las VI Jornadas de Jóvenes Investigadores en Ciencias Antropológicas, editado por A. Cetti, A. Re, D. Rindel y P. Valeri, pp. 262-279. Publicación en CD-ROM. Instituto Nacional de Antropología y Pensamiento Latinoamericano, Buenos Aires.

- - - 2010. Bone bi-points: testing functional hypothesis. En Ancient and Modern Bone Artifacts from America to Russia, editado por A. Legrand-Pineau, I. Sidéra, N. Buc, E. David y V. Scheinsohn, pp. 217-225. BAR, International Series 2136, Oxford.
- - - 2011. Experimental Series and Use-Wear in Bone Tools. Journal of Archaeological Science 38:546-557.

Buc, N. y R. Silvestre 2006. Funcionalidad y complementariedad de los conjuntos líticos y óseos en el Humedal del Noreste de la Provincia de Buenos Aires: Anahí, un caso de estudio. Intersecciones en Antropología 7:129-146.

Camps-Fabrer, H. 1966. Matièreet Art Mobilierdans la Préhistoire Nord-Africaine et Saharienne. Mémoires du Centre de Recherches Anthropologiques, Préhistoriques et Ethnographiques, Paris.

Castel, J.C., F.X. Chauviere, S. Madelaine 2003. Sur os et sur dents: les "retouchoirs" aurignaciens de la Ferrassie (Savignac-de-Miremont, Dordogne). Paleo. Revue d'Archeologie Préhistorique 15:29-50.

Cristiani, E. 2008. Analisi funzionale dei manufatti in materia dura animale del Riparo Dalmeri (Altopiano della Marcesina, Trento). Prehistoria Alpina 43:259-287.

Dantas, M. y G. Figueroa 2008. Análisis Tecnológico y Funcional del Registro Cerámico del Valle de Salsacate y Pampas de Altura Adyacentes (Provincia de Córdoba, República Argentina).BAR International Series 1869, Oxford.

David, E. 2004. Fiche transformation des matières dures d'origine animale dans le Mésolithique de l'Europe du Nord. En Fiches de la Commission de Nomenclature de l'Industrie Osseuse, Cahier XI Matières et Techniques, dirigido por D. Ramseyer, pp. 113-149. Industrie de l'os Préhistorique Éditions de la Société Préhistorique Française, Paris.

D’Errico, F., L. Backwell y L. Wadley 2012. Identifying regional variability in Middle Stone Age bone technology: The case of Sibudu Cave. Journal of Archaeological Science 39:2479-2495.

Ellis, C. 1997. Factor influencing the use of stone projectile tips. An ethnographic perspective. En Projectile Technology, editado por H. Knecht, pp. 37-78. Plenum Press, New York.

González, A.1943. Arqueología del yacimiento indígena de Villa Rumipal (Provincia de Córdoba). Publicaciones del Instituto de Arqueología, Lingüística y Folklore IV. 
- - - 1949. Nota sobre la arqueología de Pampa de Olaen (Córdoba). Notas del Museo de La Plata, tomo XIV, antropología $\mathrm{N}^{\circ}$ 56:463-503.

Grayson, D. 1991. Alpine faunas from the White Mountains, California: Adaptative change in the Late Prehistoric Great Basin? Journal of Archaeological Science 18:483-506.

Grayson, D. y S. Cole 1998. Stone tool assemblage richness during the Middle and Early Upper Paleolithic in France. Journal of Archaeological Science 25:927-938.

Keeley, L. 1982. Hafting and retooling: effects on the archaeological record. American Antiquity 47:798-809.

Knecht, H. 1997. Projectile points of bone, antler and stone. Experimental exploration of manufacture and use. En Projectile Technology, editado por H. Knecht, pp. 191-213. Plenum Press, New York.

Liesauvon Lettow-Vorbeck, C. 1998. El Soto de Medinilla: faunas de mamíferos de la Edad del Hierro en el Valle del Duero (Valladolid, España). Archaeofauna 7:1-215.

Loponte, D. 2008. Arqueología del Humedal del Paraná Inferior (Bajíos Ribereños Meridionales). Asociación Amigos del Instituto Nacional de Antropología y Pensamiento Latinoamericano, Buenos Aires.

Luik, H., M. Ots y L.Maldre 2011. From the Neolithic to Bronze Age: continuity and changes in the bone artifacts in Saaremaa, Estonia. En Written in Bones. Studies on Technological and Social Contexts of Past Faunal Skeletal Remains, editado por J. Baron y B. Kufel-Diakowska, pp. 243-261. Uniwersytet Wroclawski, Wroclawski.

Marcellino, A., E. Berberián y J. Pérez 1967. El yacimiento arqueológico de Los Molinos (Dpto. de Calamuchita - Córdoba). Publicaciones del Instituto de Antropología XXVI.

Medina, M. 2009. Tendencias en el consumo prehispánico tardío de recursos faunísticos: zooarqueología de C.Pun.39 y Puesto La Esquina 1 (Córdoba, Argentina). Archaeofauna 18:119-136.

- - - 2010. Tecnología cerámica, subsistencia y uso del espacio en el Tardío Prehispánico de las Sierras de Córdoba (Argentina). Revista Werkén 13:305-322.

Medina, M. y S. Pastor 2012. Zooarqueología de sitios residenciales tardíos de las Sierras de Córdoba (Argentina, ca. 1100-300 AP): avances y perspectivas. En Temas de Arqueología, Estudios Tafonómicos y Zooarqueológicos, editado por A. Acosta, D. Loponte y L. Mucciolo, volumen II, pp. 45-66. Instituto Nacional de Antropología y Pensamiento Latinoamericano, Buenos Aires.

Medina, M., S. Grill y L. López 2008. Palinología arqueológica: su implicancia en el estudio del prehispánico tardío de las Sierras de Córdoba (Argentina). Intersecciones en Antropología 9:99-112.

Medina, M., L. López y E. Berberián 2009. Agricultura y recolección en el Tardío Prehispánico de las Sierras de Córdoba (Argentina): el registro arqueobotánico de C.Pun.39. Arqueología $15: 217-230$.

Medina, M., S. Pastor, E. Apolinaire y L. Turnes 2011. Late Holocene subsistence and social integration in Sierras of Córdoba (Argentina): the South-American ostrich eggshells evidence. Journal of Archaeological Science 28:2071-2078.
Menghin, O. y A. González 1954. Excavaciones arqueológicas en el yacimiento de Ongamira, Córdoba (Rep. Arg.). Nota preliminar. Notas del Museo de La Plata, tomo XVII, antropología 67:213-274.

Mozota Holgueras, M. 2008. Estudio tafonómico y tecnológico de un útil doble "cincel/retocador", proveniente del nivel c (Musteriense) de Axlor-Dima, Bizkaia. Zephyrus 61:217-224.

Mujika Alustiza, A. 2008. La gestión de la materia prima ósea en la fabricación de objetos durante la prehistoria. Veleia 24-25:531-568.

Nami, H. y V. Scheinsohn 1997. Use-wear patterns on bone exerimental flakers: a preliminary report. Proceedings of the 1993 Bone Modification Conference, Hot Springs, South Dakota, editado por L. A. Hannus, L. Rossum y R. P. Winhan, pp. 256-264. Archaeology Laboratory, Agusana College, Sioux Falls, South Dakota.

Nelson, M. 1991. The study of technological organization. Advances in Archaeological Method and Theory 3:57-100.

Pastor, S. 2007. "Juntas y cazaderos". Las actividades grupales y la reproducción de las sociedades prehispánicas de las Sierras Centrales de Argentina. En Procesos Sociales Prehispánicos en el Sur Andino: la Vivienda, la Comunidad y el Territorio, editado por A. Nielsen, V. Seldes, M. Vázquez y P. Mercolli, pp. 361-376. Editorial Brujas, Córdoba.

- - - 2010. Aproximación inicial a la arqueología del norte de la sierra de Guasapampa y cordón de Serrezuela (Córdoba, Argentina). Arqueología 16:151-174.

Pastor, S. y M. Medina 2005. El uso prehispánico tardío de los ambientes serranos de altura. Investigaciones arqueológicas en la Pampa de Achala, de San Luis y de Olaen (Córdoba, Argentina). La Zaranda de Ideas 1:39-54.

Pastor, S., M. Medina, A. Recalde, L. López y E. Berberián 2012. Arqueología de la región montañosa central de Argentina. Avances en el conocimiento de la historia prehispánica tardía. Relaciones de la Sociedad Argentina de Antropología XXXVII(1):89-112.

Pastor, S. y D. Rivero 2009. El diseño y la composición de los equipamientos de caza de las comunidades formativas de las Sierras de Córdoba. Arqueología Argentina en los Inicios de un Nuevo Siglo, Publicación del XIV Congreso Nacional de Arqueología Argentina, tomo II, pp. 275-289. Universidad Nacional de Rosario, Rosario.

Pastor, S., D. Rivero y E. Pautassi 2005. Los sistemas de armas de las comunidades agroalfareras de Córdoba: una aproximación arqueológica y experimental. Actas del XIII Congreso Nacional de Arqueología Argentina, tomo IV, pp. 253-266. Córdoba.

Petillon, J. 2006. Des Magdaleniens en Armes Technologie de Projectile en Bois de Cervide du Magdelenien Supereueur de la Grotte D'Isturitz (Pyrenees-Atantiques). Editions du Centre D'Etudes et de Documentation Archéologiques, Treignes.

Ratto, N. 2003. Estrategias de Caza y Propiedades de Registro Arqueológico en la Puna de Chaschuil (Dpto. de Tinogasta, Catamarca, Argentina). Tesis para optar al grado de Doctor en Ciencias Antropológicas, Facultad de Filosofía y Letras, Universidad de Buenos Aires, Buenos Aires.

Recalde, A.2008-09. Movilidad estacional y representaciones rupestres. Primeras evidencias de ocupaciones estivales vinculadas 
con la explotación de ambientes chaqueños en las Sierras de Córdoba. Anales de Arqueología y Etnología 63-64:57-80.

Rivero, D. 2009. Ecología de Cazadores-Recolectores en el Sector Central de las Sierras de Córdoba (República Argentina). BAR International Series 2007, Oxford.

Rivero, D., M. Medina, A. Recalde y S. Pastor 2010. Variabilidad en la explotación de recursos faunísticos durante el Holoceno en las Sierras de Córdoba (Argentina): una aproximación zooarqueológica. En Zooarqueología a Principios del Siglo XXI: Aportes Teóricos, Metodológicos y Casos de Estudio, editado por M. Gutiérrez, M. De Nigris, P. Fernández, M. Giardina, A. Gil, A. Izeta, G. Neme y H. Yacobaccio, pp. 321-332. Ediciones del Espinillo, Buenos Aires.

Rivero, D., S. Pastor y M. Medina 2008-09. Intensificación en las Sierras de Córdoba. El abrigo rocoso Quebrada del Real 1 (ca. 6500-500 AP, Córdoba, Argentina). Anales de Arqueología y Etnología 63-64:227-246.

Santander, B. y P. López 2012. Análisis de microhuellas de uso mediante microscopio de barrido (MEB) de artefactos óseos de un sitio arcaico tardío del valle de Mauro (región de Coquimbo, Chile): Aportes para una reconstrucción contextual. Revista Chilena de Antropología 26:129-150.

Scheinsohn, V. 1997. Explotación de Materias Primas Óseas en la Isla Grande de Tierra del Fuego. Tesis para optar al grado de Doctor en Ciencias Antropológicas, Facultad de Filosofía y Letras, Universidad de Buenos Aires, Buenos Aires.

Schlanger, S. y J. Orcutt 1986. Site surface characteristics and functional inferences. American Antiquity 51:296-312.

Serrano, A. 1945. Los Comechingones. Serie Aborígenes Argentinos I. Instituto de Arqueología, Lingüística y Folklore, Córdoba.

Shipman, P., G. Foster y M. Schoeninger 1984. Burnt bones and teeth: an experimental study of colours, morphology, crystal structure and shrinkage. Journal of Archaeological Science 11:307-425

Stone, E. 2011. Through the Eye of the Needle: Investigations of Ethnographic, Experimental, and Archaeological Bone Tool Use Wear from Perishable Technologies. PhD dissertation, University of New Mexico.

Vitezovic, S. 2011. The Neolithic bone industry from Drenovac, Serbia. En Written in Bones. Studies on Technological and Social Contexts of Past Faunal Skeletal Remains, editado por J. Baron y B. Kufel-Diakowska, pp. 117-135.Uniwersytet Wroclawski, Wroclawski.

Yesner, D. y R. Bonnichsen 1979. Caribou metapodial shaft splinter technology. Journal of Archaeological Science 6:303-308.

\section{Notas}

1 No se detectó ninguna traza en los restos faunísticos que pueda asociarse con el impacto de puntas de proyectil, siendo una línea de evidencia que debe ser profundizada en futuros trabajos.

2 La presencia de huesos de lagarto Tupinambis y cáscaras de huevo de Rheidae, junto con evidencias de actividades agrícolas-semillas, instrumentos agrícolas, polen de malezas, etc.-y de recolección-Prosopis cf. P. nigra, Phaseolus vulgaris var. aborigenus y Geoffroea decorticans-, sugiere que la ocupación de los sitios coincidió con primavera-verano, momento del año que debe realizarse la siembra y están disponibles los recursos silvestres en el entorno inmediato (Medina et al. 2009; Medina y Pastor 2012). 